\title{
Knowledge, attitudes, beliefs and practices in Lebanon concerning HIV/AIDS, 1996-2004
}

J.G. Kahhaleh, ${ }^{1}$ M. El Nakib ${ }^{2}$ and A.R. Jurjus ${ }^{1}$

$$
\begin{aligned}
& \text { المعارف والمواقف والمعتقدات والملارسات حول الإيدز و العدوى بفيروسه في لبنان } 1996 \text { - } 2004
\end{aligned}
$$

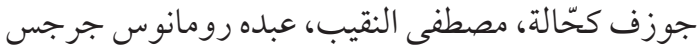

الخلاصسة: استهدفت هذه الدراسة الشاملة للقطاعات تقييم أثر التدخلات الوقائية من فيروس الإيدز في لبنان

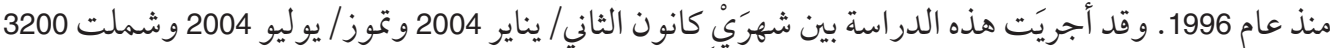

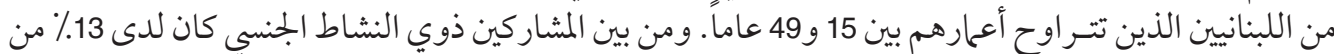

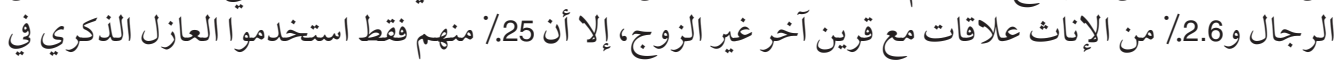

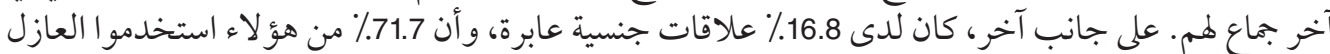

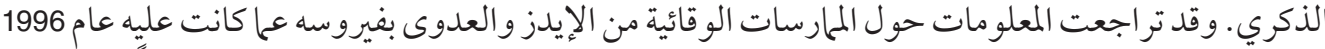

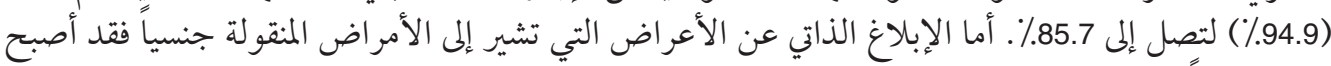

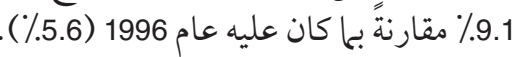

ABSTRACT This cross-sectional study, aimed at evaluating the impact of HIV prevention interventions in Lebanon since 1996, was performed between January 2004 and July 2004 on 3200 Lebanese aged $15-49$ years. Of the sexually active respondents, $13.0 \%$ of men and $2.6 \%$ of women had regular partners other than the spouse but only $25.0 \%$ used a condom in their last sexual intercourse. However, $16.8 \%$ had sex with casual partners and $71.7 \%$ of those used a condom. Knowledge about preventive practices against HIV/AIDS has regressed since 1996, $85.7 \%$ compared to $94.9 \%$. Self reports of symptoms suggestive of sexually transmitted disease were $9.1 \%$ compared to $5.6 \%$ in 1996 .

Connaissances, attitudes, croyances et pratiques au Liban à propos du VIH/sida de 1996 à 2004

RÉSUMÉ Cette étude transversale, qui visait à évaluer l'impact des interventions de prévention du VIH au Liban depuis 1996, a été réalisée de janvier à juillet 2004 sur 3200 Libanais âgés de 15 à 49 ans. Parmi les personnes sexuellement actives interrogées, 13,0 \% des hommes et 2,6 \% des femmes avaient régulièrement d'autres partenaires que leur conjoint, mais seulement $25,0 \%$ avaient utilisé un préservatif au cours de leur dernier rapport. Par ailleurs, 16,8 \% avaient des rapports avec des partenaires occasionnels et $71,7 \%$ d'entre eux utilisaient un préservatif. Les connaissances relatives aux pratiques de prévention contre le $\mathrm{VIH} /$ sida ont diminué depuis 1996, en passant de $94,9 \%$ à $85,7 \%$. Le pourcentage de personnes déclarant présenter des symptômes évocateurs d'une maladie sexuellement transmissible était de 9,1\%, contre 5,6\% en 1996.

'Lebanese Health Society, Beirut, Lebanon (Correspondence to A.R. Jurjus: ajo0@aub.edu.Ib). ${ }^{2}$ National AIDS Programme, Ministry of Health, Beirut, Lebanon.

Received: 19/03/06; accepted: 17/09/06 


\section{Introduction}

\section{Background}

Worldwide, up to the end of 2002, the human immunodeficiency virus (HIV) had infected approximately 67 million people. More than 25 million have already died from acquired immunodeficiency syndrome (AIDS) (about 3.1 million deaths in 2002 alone, including 610000 children), ranking it as one of the leading causes of death. The remaining 42 million have been living with HIV infection or AIDS [1].

In the World Health Organization Eastern Mediterranean Region, an estimated 700000 people are living with HIV/AIDS, but only 14198 AIDS cases have been officially registered since the start of the epidemic [2]. Complete data were lacking for 11 of the 22 countries of the Region for 2003. Based on available figures, the Regional epidemic is being driven largely by heterosexual transmission, which represents almost $80 \%$ of the cumulative total of AIDS cases reported.

In Lebanon, the first reported AIDS case was in 1984 [3]; the number steadily increased to 765 reported cases by July 2004 [4]. Although a significant proportion of these (around $45 \%$ ) were linked to travel and migration to (and return from) endemic areas, local spread had become a reality. The most frequent mode of transmission was sexual $(77.25 \%)$, mainly heterosexual $(52.70 \%)$ [4].

The highest number of cases was in the age group 31-40 years, with a ratio of men:women of 8.5:1 [4]. The majority of the cases reported to the National AIDS Programme (NAP) were increasingly at the stage of AIDS disease rather than asymptomatic HIV infection. This indicates that the individuals probably acquired the infection at a younger age, yet had not been tested for HIV until they were symptomatic. Moreo- ver, an increasing trend of new reports of HIV and AIDS cases was noticed within the younger population (15-29 years) compared to a horizontal trend in the other age groups.

As a national response to the epidemic, the Lebanese government declared in 1988 that HIV/AIDS was a threat to public health, and in 1989 the NAP was established. It primarily performed activities based on short-term action plans in accordance with the local epidemiological situation; needs assessment; knowledge, attitudes, beliefs and practice studies; and World Health Organization directives [5].

\section{Interventions}

In July 1994, a consensus workshop formulated a medium-term plan that set priorities for NAP activities for 1995-2000 [6]. It identified target groups, described barriers and proposed solutions and intervention priorities. These interventions were:

- promoting safe sex,

- promoting condom use and increasing availability,

- promoting safe behaviour to avoid sexually transmitted diseases,

- promoting the application of universal precautions in the health centres,

- promoting and controlling the safety of blood,

- increasing awareness on the risks of HIV transmission among the intravenous drug users,

- providing support and care to persons infected with HIV/AIDS and their families,

- conducting research targeting groups that are at a higher risk of HIV transmission. 
For the implementation of the above, the NAP developed awareness campaigns and support materials. It organized advocacy campaigns through community participation and capacity-building. Along with the Infectious Diseases Society, it developed protocols for disease management, updated on a yearly basis. In addition, several acts or mandates related to HIV control were put into laws or decrees, e.g. those related to the safety of blood, mandatory declaration, confidentiality, non-discrimination, compulsory testing of high-risk groups (e.g. female sex workers) and work permits for foreigners.

\section{Assessment}

In 1996, an assessment study on knowledge, attitudes, beliefs and practices (KABP) of the general population in Lebanon showed almost universal awareness of HIV/AIDS (95.5\%) [5].

The present study is an evaluation of the HIV/AIDS indicators and makes comparisons with those measured in 1996. It is a re-assessment among the general population of:

- trends of change in risky practices,

- knowledge of modes of transmission,

- knowledge of preventive practices,

- prevalence of risky sexual behaviours,

- incidence of self-reported sexually transmitted disease (STD) symptoms.

\section{Methods}

\section{Sample population}

This cross-sectional study was conducted on a representative sample of 3200 participants from Lebanon aged 15-49 years.

Using Altman's nomogram for sample size calculation yields a sample size of 3200 for a power between 70 and 80, a standard- ized difference of 10 and a significance level of 0.1

This survey was carried out during the period January 2004-March 2004 using a stratified cluster sample design. The country was first stratified by governorate ( $\mathrm{mo}$ hafazat) and district levels in order to select the primary sampling units. Once these were identified, they were subdivided into clusters, and then by systematic random sampling, households were selected for interviewing. Sample size in each governorate was proportional to the population.

All persons aged 15-49 years were included whether they were regular residents of the household or had spent the night before the interview in the household. Regular household members who were temporarily away from home were included as household members and interviewed during a later visit.

\section{Survey instrument and data collection}

The survey instrument was a questionnaire that was adapted and adopted for repeated survey of the general population as described in Evaluation of a national AIDS programme: a methods package [7]. It consisted of 2 parts, Part A, the household schedule, the purpose of which was to identify all persons eligible for the individual interview and Part $\mathrm{B}$, the individual questionnaire for men and women aged 15-49 years. This was divided into 8 sections: (1) identification and demographic data, (2) background characteristics, including source of information on health issues and media, (3) marriage and regular partners, (4) non-regular commercial sex, (5) condoms, (6) STDs and health issues (divided into 2 parts, one for men only and the second for women only), (7) knowledge of AIDS, (8) risk perception, behaviour change and attitudes to persons with HIV/AIDS. 
The average time taken to complete each questionnaire was $20-25$ minutes. The questionnaire was used as a verbatim instrument after translation into Arabic and being pre-tested on 100 people.

The interviewers worked in teams of 1 male and 1 female in addition to the supervisor. Male respondents were interviewed by men and female respondents by women.

\section{Results}

\section{Population characteristics, sample validity and sampling}

The sample consisted of 3200 respondents; $58.6 \%$ (1876) were males, giving an overall male/female ratio of 1.4 .

The average number of respondents per household (2.2) was low: in many cases, after 1 person in the family answered the questions and discovered that they were very sensitive and touched on very personal issues, the rest of the family apologized for not continuing. It was estimated by supervisors and interviewers that around $15 \%$ in the cities and up to $25 \%$ elsewhere refused to participate in the study despite the anonymous nature of the exercise. However, the overall response rate per household was better than the 1.41 reported in 1996.

The sample represents well a relatively young population: $64.5 \%$ were $<35$ years old (Table 1). The great majority, $96.0 \%$ (3073), had attended school, however, $10.7 \%$ (343) had attended only primary school, so if literacy is considered as being educated beyond primary school, then $14.7 \%$ would be considered illiterate (comparable to the illiteracy rate often reported for Lebanon, i.e. about $10 \%-15 \%$ ), mostly in the age category $45-49$ years. These rates were similar to those in the 1996 survey. However, a higher percentage of people, $7.1 \%$ compared to $6.3 \%$ in 1996 , reported that they could not read (Table 2).

\begin{tabular}{|c|c|c|c|c|}
\hline \multirow[t]{2}{*}{ Characteristic } & \multicolumn{2}{|c|}{ Total } & \multicolumn{2}{|c|}{ Married } \\
\hline & No. & $\%$ & No. & $\%$ \\
\hline$\overline{\text { Total }^{a}}$ & 3200 & 100.0 & 760 & 23.8 \\
\hline \multicolumn{5}{|l|}{ Sex } \\
\hline Male ${ }^{b}$ & 1876 & 58.6 & 503 & 26.8 \\
\hline Female $^{c}$ & 1324 & 41.4 & 257 & 19.4 \\
\hline \multicolumn{5}{|l|}{ Age (years) } \\
\hline $15-24$ & 1040 & 32.5 & 43 & 5.7 \\
\hline $25-34$ & 1024 & 32.0 & 255 & 33.6 \\
\hline $35-44$ & 768 & 24.0 & 294 & 38.7 \\
\hline $45-49$ & 368 & 11.5 & 168 & 22.1 \\
\hline \multicolumn{5}{|l|}{ Education level } \\
\hline No school & 127 & 4.0 & 37 & 29.1 \\
\hline Primary & 343 & 10.7 & 125 & 36.4 \\
\hline Complementary $^{d}$ & 795 & 24.8 & 240 & 30.2 \\
\hline Secondary & 786 & 24.6 & 176 & 22.4 \\
\hline University student & 286 & 8.9 & 1 & 0.3 \\
\hline University graduate & 863 & 27.0 & 181 & 21.0 \\
\hline
\end{tabular}

\section{Media and information on health issues}

The highest daily rate for media use was for TV, 97.6\%. Health articles or reports proved to be almost equally read in newspapers and magazines, $32.5 \%$, as listened to on the radio, $31.3 \%$, however health reports were mostly watched on TV, $54.4 \%$, and this was considered the best primary source of health information, $33.6 \%$ (Table 2).

\section{Marriage and regular partnerships}

We found $52.0 \%$ of the sample had ever been married compared to $44.2 \%$ in 1996 (Table 3). Just under half of those ever married were still married at the time of the study compared to $87.4 \%$ in 1996 . Females got married earlier than males: $35.6 \%$ of females were married before the age of 20 years compared to only $5.0 \%$ of males 


\begin{tabular}{|c|c|c|c|c|}
\hline \multirow[t]{2}{*}{ Variable } & \multirow{2}{*}{$\begin{array}{c}1996(n=1504) \\
\%\end{array}$} & \multicolumn{2}{|c|}{$2004(n=3200)$} & \multirow{2}{*}{$\begin{array}{c}P \text { for } \\
90 \% \mathrm{Cl}\end{array}$} \\
\hline & & No. & $\%$ & \\
\hline \multicolumn{5}{|l|}{ Education } \\
\hline Attended school & 97.8 & 3073 & 96.0 & 0.0008 \\
\hline $\begin{array}{l}\text { Primary school } \\
\text { only }\end{array}$ & 11.6 & 343 & 10.7 & NS \\
\hline Low education & 14.0 & & 14.7 & NS \\
\hline Cannot read & 6.3 & 277 & 7.1 & NS \\
\hline Married & 44.2 & 760 & 23.8 & $>0.0001$ \\
\hline Mobility ${ }^{a}$ & 5.3 & & 1.3 & $>0.0001$ \\
\hline Sexually active & 63.8 & & 66.8 & 0.0222 \\
\hline \multicolumn{5}{|l|}{ Media daily use } \\
\hline TV & 88.2 & 3124 & 97.6 & $>0.0001$ \\
\hline Radio & 63.8 & 1355 & 42.3 & $>0.0001$ \\
\hline Magazines & 27.3 & 594 & $18.6^{b}$ & $>0.0001$ \\
\hline \multicolumn{5}{|l|}{ Health reports } \\
\hline Read & 49.1 & $996^{c}$ & 33.5 & $>0.0001$ \\
\hline Listen to & 41.8 & $796^{d}$ & 31.3 & $>0.0001$ \\
\hline Watch & 56.9 & $1700^{e}$ & 54.4 & 0.0668 \\
\hline $\begin{array}{l}\text { Best source of } \\
\text { health information }\end{array}$ & 79.3 & & 54.4 & \\
\hline Television & 39.1 & 1075 & 33.6 & $>0.0001$ \\
\hline Newspaper & 27.8 & 522 & 16.3 & $>0.0001$ \\
\hline Radio & 12.4 & 144 & 4.5 & $>0.0001$ \\
\hline \multicolumn{5}{|l|}{ Married $<20$ years } \\
\hline Females & 44.2 & $272^{f}$ & 35.6 & - \\
\hline Males & 9.6 & $45^{9}$ & 5.0 & - \\
\hline
\end{tabular}

(Table 2). The comparable figures for 1996 were $44.2 \%$ and $9.6 \%$.

Unmarried respondents comprised $76.2 \%$ compared to $61.4 \%$ in 1996 (Table 3 ). Just over half the males $56.3 \%$ (1373) were not married, more living in urban areas and more with university education. Early marriage (under age 20 years) was reported more among females $(272 / 764 ; 33.6 \%)$, among whom the higher the level of education the lower the rate of marriage.

Sexual activity was experienced early in life: $36.0 \%$ first had sexual intercourse at $\leq 20$ years in 2004 compared to $64.5 \%$ in 1996 (Table 4). Among the males, if we include those who were ever married and those who were unmarried but sexually active, in $200470.5 \%$ of males were sexually active; among females this was $61.6 \%$ (Table 5). The corresponding values for 1996 were $73.2 \%$ for males and $54.3 \%$ for females.

Therefore, a good proportion of sexually active, unmarried young people, mostly males, were engaging in sex with a regular partner $(13.0 \%)$, multiple partners $(19.4 \%$ 


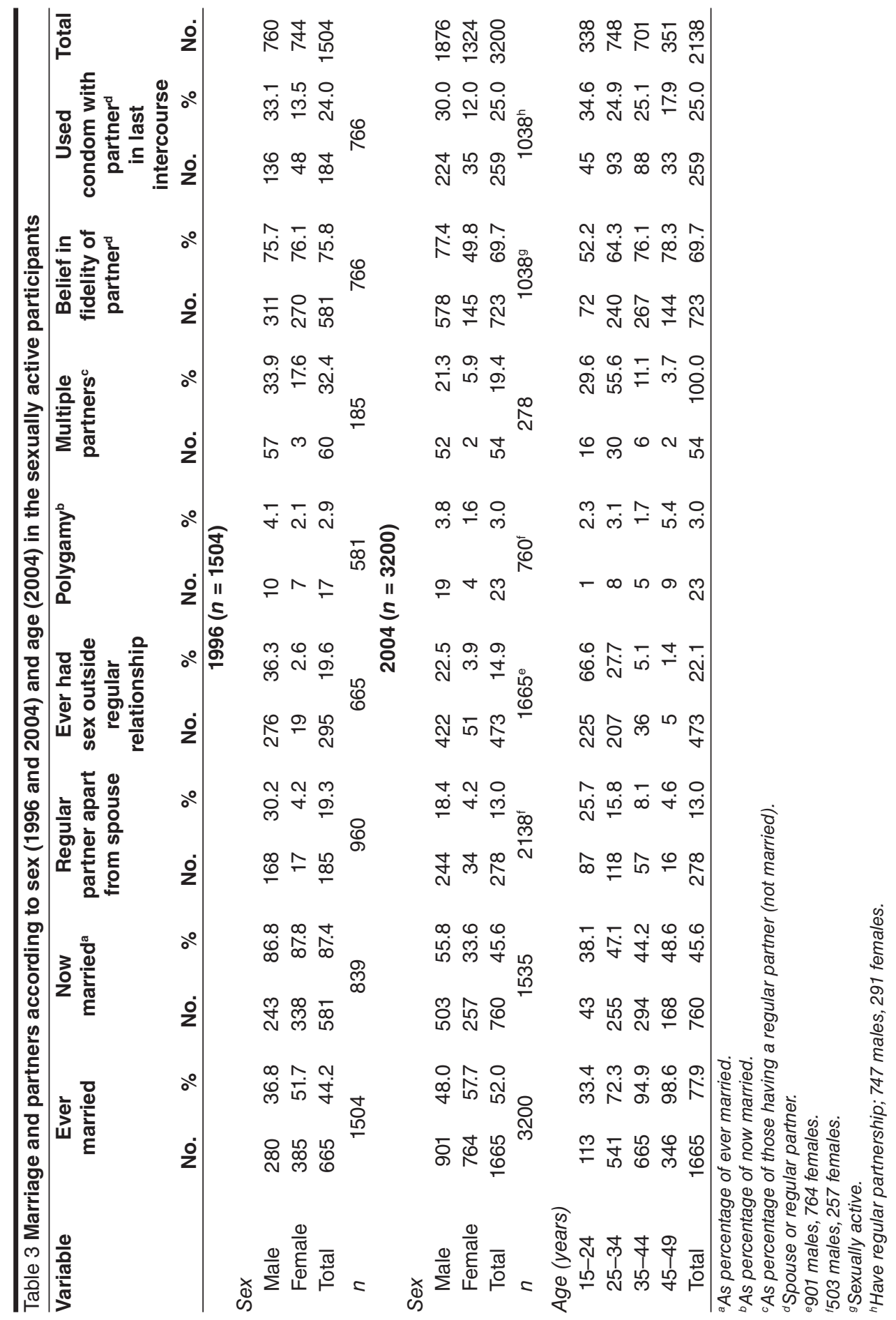

المجلة الصحية لشرق المتوسط، منظمة الصحة العالمية، المجلد الخامس عشر، العدد ع، 9 +.ب 
of the 278 having regular partners), or casual partners (16.8\%) (Tables 3 and 5).

Among those who had a regular partner apart from the spouse, most were educated beyond primary school level. The highest rates of condom use in this group were for students, $36.8 \%$ (14 out of 38 ) and university graduates, $33.7 \%$ (87 out of 258) (data not shown).

Younger respondents $(<25$ years $)$ who were not married and were sexually active constituted the category that had the highest rate of condom use during their last sexual intercourse, $34.6 \%$ (45 of 130 who ever used a condom), and the highest rates of having a regular partner, 25.7\% (Table 3) (comparable data from 1996 not available).

Males showed a complete dominance in having sex outside marriage and having multiple partners (Table 3 ). Using a condom with a regular partner was also much more frequent in males. However, it was evident that the rate of sexual activity, for both non-married and married, was much higher than the rate of condom use.

\section{Casual partners and commercial sex}

As shown in Table 5, 16.8\% (360 out of 2138) of the sexually active respondents had had casual sex in the previous 12 months in the 2004 survey compared to $22.4 \%$ (215 of 960) in 1996 . These were predominantly young, urban males, mostly students. Around two-thirds

\begin{tabular}{|c|c|c|c|c|}
\hline \multirow[t]{2}{*}{ Age (years) } & \multicolumn{2}{|c|}{1996} & \multicolumn{2}{|c|}{2004} \\
\hline & No. & $\%$ & No. & $\%$ \\
\hline$\geq 10$ & 16 & 1.7 & 1 & $<1.0$ \\
\hline $11-14$ & 152 & 15.8 & 36 & 1.7 \\
\hline $15-20$ & 451 & 47.0 & 711 & 33.3 \\
\hline $21-25$ & 162 & 16.9 & 169 & 7.9 \\
\hline $26+$ & 64 & 6.7 & 54 & 2.5 \\
\hline Did not respond & 115 & 12.0 & 1167 & 54.6 \\
\hline Total & 960 & 100.0 & 2138 & 100.0 \\
\hline
\end{tabular}

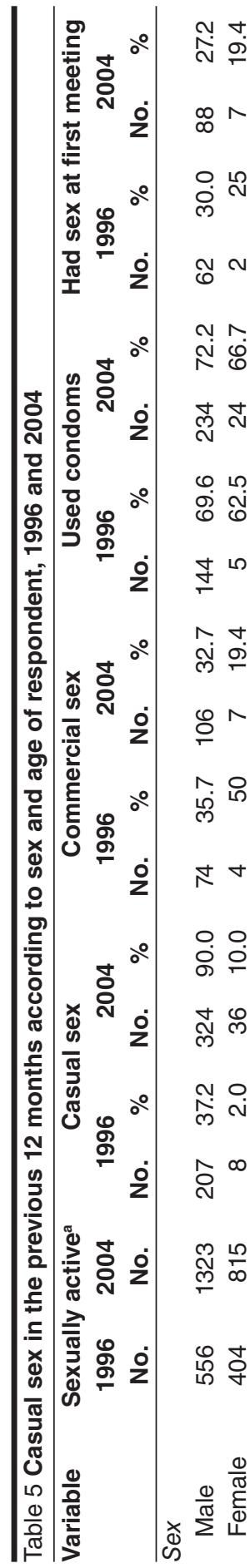


(238 of 360$)$ had $\geq 2$ partners. Just over $30 \%$ of those involved with non-regular partners stated that they gave or received money or gifts in exchange for sex (commercial sex); for $26.4 \%$ of these the sexual encounter was during the first meeting.

Age was a prominent factor in casual sex: in $200437.9 \%$ of the sexually active respondents aged 15-24 years had casual sex and this decreased with age (Table 5). However, the proportion having commercial sex and sex at their first meeting generally increased with age. The corresponding figure for 1996 was $29.8 \%$.

\section{Condom use}

Within marriage or regular partnership, the use of condoms at the last intercourse was only $25.0 \%$ in 2004 , similar to the $23.7 \%$ in 1996 (Table 3). Condom use was relatively much lower in the youngest age group (Table 5). Although $84.1 \%$ had heard about condoms, only $15.3 \%$ overall had used one, which compares unfavourabl with the $95.1 \%$ and $32.5 \%$ respectively in 1996 (Table 6). Compared with the 1996 survey, we noted a decrease in rates for all parameters except for having seen a condom and use with regular and with non-regular partners (Tables 6 and 7).

\section{Sexually transmitted disease}

Self reported symptoms of STD (pain during urination or discharge from penis) in the previous 12 months were reported by $12.4 \%$ of sexually active males in 2004 (Table 8), a statistically significant increase compared to $1996(5.6 \%)(P<0.0001)$. They were almost equally distributed between rural 9.9\% (68 of 689 ) and urban $8.4 \%$ (53 of 634). A higher number of episodes were reported in those aged $\geq 35$ years (Table 8 ).

Just over $35 \%$ of those reporting having symptoms of STD sought professional treatment in 2004, while $15.1 \%$ said they did nothing (Table 9); corresponding values for 1996 were $78.5 \%$ and 16.7\%. Attitude towards partners varied greatly, $37.2 \%$ told their partners about their suspected STD and $43.8 \%$ took preventive or curative measures (mainly refraining from sexual intercourse) in 2004; this compares poorly with $59.5 \%$ and $73.8 \%$ respectively in 1996 . What aggravated risky behaviour was the presence of recurrent episodes in many cases (19.0\% in 2004 and 47.6\% in 1996). There were also a number of respondents who had multiple, non-regular sex partners, and condoms were only occasionally used as a protective measure.

Of the sexually active women participating in the study, $13.9 \%$ had had a child in the previous 2 years, $92.4 \%$ of whom had seen a health worker. This was excellent coverage since $98 \%$ of these reported having had an examination of the vagina.

\section{Knowledge of AIDS}

Awareness about HIV/AIDS was $98.2 \%$ in 2004. Those who were not aware of HIV/ AIDS were predominantly non-schooled, female, and lived in the South or the Bekaa.

\begin{tabular}{lccccc}
\hline \multicolumn{7}{l}{ Table 6 Comparison of condom knowledge, 1996 and $\mathbf{2 0 0 4}$} \\
\hline Knowledge item & $\mathbf{1 9 9 6}(\boldsymbol{n}=\mathbf{1 5 0 4})$ & $\mathbf{2 0 0 4}(\boldsymbol{n}=\mathbf{3 2 0 0})$ & $\boldsymbol{P}$ for $\mathbf{9 0 \%} \mathbf{~ C l}$ \\
& No. & $\%$ & No. & $\%$ & \\
\hline Heard about condoms & 1430 & 95.1 & 2692 & 84.1 & $<0.0001$ \\
Seen a condom & 1071 & 71.2 & 2558 & 79.9 & $\mathrm{NS}$ \\
Knowledge of outlets & 1355 & 90.1 & 2398 & 74.9 & $<0.0001$ \\
Used a condom & 489 & 32.5 & 490 & 15.3 & $<0.0001$ \\
\hline Cl = confidence interval; $N S=$ not significant
\end{tabular}

المجلة الصحية لشرق المتو سط، منظمة الصحة العالمية، المجلد الخامس عشر، العدد ع، 9 +. 


\begin{tabular}{|c|c|c|c|c|c|c|}
\hline \multirow[t]{2}{*}{ Use category } & \multicolumn{3}{|c|}{1996} & \multicolumn{3}{|c|}{2004} \\
\hline & $\begin{array}{c}\text { Sample } \\
\text { size }\end{array}$ & No. & $\%$ & $\begin{array}{c}\text { Sample } \\
\text { size }\end{array}$ & No. & $\%$ \\
\hline Used by the sexually active & 960 & 489 & 50.9 & 2138 & 312 & 14.6 \\
\hline Used with regular partners & 778 & 184 & 23.7 & 760 & 246 & 32.4 \\
\hline Used with non-regular partners & 215 & 149 & 69.3 & 363 & 257 & 70.8 \\
\hline $\begin{array}{l}\text { Used by those who self report } \\
\text { STD symptoms } \\
\text { Know that condoms protect }\end{array}$ & 42 & 13 & 31.0 & 152 & 22 & 14.5 \\
\hline from HIV & 1496 & 1326 & 88.6 & 3141 & 2743 & 87.3 \\
\hline
\end{tabular}

STD = sexually transmitted disease.

A comparison of the prevention indicators in Lebanon in 1996 and 2004 is shown in Table 10. Knowledge of preventive practices and condom availability had statistically significantly deteriorated and the rate for self-reported STDs had significantly increased.

Knowledge of valid practices such as staying faithful to one partner, use of clean needles and syringes or using condoms as means of protection from HIV/AIDS had worsened since the 1996 survey and the situation regarding invalid measures had also deteriorated (Table 11). The most common misconception in both surveys was to avoid public toilets. The next most common was to avoid insect bites, $27.7 \%$ in 1996 and $27.3 \%$ in 2004 .

\section{Effect on beliefs, attitudes and lifestyle in people who had heard about HIVIAIDS}

Our data showed that $6.8 \%$ of the participants knew someone with HIV/AIDS in 2004 (Table 12). Nevertheless, 67.5\% perceived no risk of being infected with HIV. Only $1.1 \%$ felt they had a good chance of acquiring the infection. Actually, only $24.1 \%$ reported having made behavioural changes because of HIV/AIDS, and 20.2\% of those had made the changes in the previous 12 months.
The perception of being protected against contracting HIV was greater among females (Table 12). They reported fewer changes in sexual behaviour than males, $19.8 \%$ compared to $27.1 \%$, and they were more willing to care for a family member with AIDS: $65.8 \%$ compared to $55.2 \%$.

About two-thirds stated that people having HIV/AIDS should be allowed to continue their work and not be discriminated against in the workplace (Table 12). Positive attitudes were not dependent on the respondents' education or area of residence. In contrast, however, only $29.1 \%$ believed that HIV positivity should not be revealed. These questions were not included in the 1996 survey, so it was not possible to make a comparison.

\begin{tabular}{|c|c|c|c|}
\hline \multirow[t]{2}{*}{ Age (years) } & \multirow{2}{*}{$\begin{array}{c}\text { Total } \\
\text { No. }\end{array}$} & \multicolumn{2}{|c|}{ Symptomatic ${ }^{a}$} \\
\hline & & No. & $\%$ \\
\hline 15-24 & 225 & 26 & 11.6 \\
\hline $25-34$ & 459 & 45 & 9.8 \\
\hline $35-44$ & 385 & 57 & 14.8 \\
\hline $45-49$ & 254 & 36 & 14.2 \\
\hline $25-49$ & 1098 & 138 & 12.6 \\
\hline Total & 1323 & 164 & 12.4 \\
\hline
\end{tabular}


Eastern Mediterranean Health Journal, Vol. 15, No. 4, 2009

\begin{tabular}{|c|c|c|c|c|c|}
\hline \multirow[t]{2}{*}{ Variable } & \multicolumn{2}{|c|}{$1996(n=760)$} & \multicolumn{2}{|c|}{$2004(n=1323)$} & \multirow[t]{2}{*}{$P$ for $90 \% \mathrm{C}$} \\
\hline & No. & $\%$ & No. & $\%$ & \\
\hline Self-reported episode of STD & 42 & 5.6 & 152 & 11.5 & 0.0001 \\
\hline \multicolumn{6}{|l|}{ Action } \\
\hline Sought professional treatment & 33 & 78.5 & 57 & 37.5 & $<0.0001$ \\
\hline Recurrent episode & 20 & 47.6 & 23 & 15.1 & 0.0001 \\
\hline Advice of a friend & 20 & 47.6 & 35 & 23.0 & 0.0003 \\
\hline Did nothing & 7 & 16.7 & 23 & 15.1 & NS \\
\hline Used self-medication & 7 & 16.7 & 33 & 21.7 & NS \\
\hline \multicolumn{6}{|l|}{ Attitude to partner } \\
\hline Took preventive measures & 31 & 73.8 & 53 & 34.9 & $<0.0001$ \\
\hline Informed partner & 25 & 59.5 & 45 & 29.6 & $<0.0001$ \\
\hline Refrained from sexual intercourse & 23 & 54.8 & 120 & 78.9 & NS \\
\hline Used condoms & 13 & 30.9 & 30 & 19.7 & 0.0023 \\
\hline $\begin{array}{l}\text { Advised partner to have medical } \\
\text { consultation }\end{array}$ & 7 & 16.7 & 6 & 3.9 & 0.0001 \\
\hline
\end{tabular}

\section{Discussion}

It was clear from the pre-testing stage that we were dealing with a very sensitive issue and that we were exploring the intimate personal life of the respondents. This was reflected in the low average number of respondents per household (2.2). However, the overall response rate was better than the 1.41 per household reported in 1996 [5]. This increased rate may be a result of the increased awareness and perceived risk of the problem among the population.
Many families were young and did not have children in the eligible age group at home. This is evident from the relatively higher numbers in the young age groups in the sample and the higher percentage of marriages in the age group 25-34 years [5].

\section{Media and information on health issues}

Health programmes were mostly watched on TV, which was considered the best primary source on health information. There was an overall decrease with respect to

\begin{tabular}{|c|c|c|c|c|c|c|c|}
\hline \multirow[t]{2}{*}{ Indicator } & \multicolumn{3}{|c|}{1996} & \multicolumn{3}{|c|}{2004} & \multirow[t]{2}{*}{$P$ for $90 \% \mathrm{Cl}$} \\
\hline & Total & No. & $\%$ & Total & No. & $\%$ & \\
\hline $\begin{array}{l}\text { Knowledge of preventive } \\
\text { practices }\end{array}$ & 1504 & 1427 & 94.9 & 3200 & 2743 & 85.7 & $<0.0001$ \\
\hline $\begin{array}{l}\text { Condom availability outside } \\
\text { city centre }\end{array}$ & 1504 & 1355 & 90.1 & 3200 & 2333 & 72.9 & $<0.0001$ \\
\hline $\begin{array}{l}\text { Condom use with non-regular } \\
\text { sex partners }\end{array}$ & 205 & 145 & 70.7 & 361 & 257 & 71.2 & 0.4562 \\
\hline Non-regular sexual partners & 825 & 205 & 24.8 & 2138 & 361 & 16.9 & $<0.0001$ \\
\hline Self-reported STD (men) & 760 & 42 & 5.5 & 1323 & 121 & 9.1 & $<0.0001$ \\
\hline
\end{tabular}

$\overline{C l}=$ confidence interval; $S T D=$ sexually transmitted disease . 


\begin{tabular}{|c|c|c|c|c|c|}
\hline \multirow[t]{2}{*}{ Method } & \multicolumn{2}{|c|}{$1996(n=1496)$} & \multicolumn{2}{|c|}{$2004(n=3142)$} & \multirow[t]{2}{*}{$P$} \\
\hline & No. & $\%$ & No. & $\%$ & \\
\hline \multicolumn{6}{|l|}{ Valid } \\
\hline $\begin{array}{l}\text { Using clean needles for } \\
\text { injections }\end{array}$ & 1447 & 96.7 & 2702 & 86.0 & - \\
\hline $\begin{array}{l}\text { Staying faithful to one partner } \\
\text { Using condoms during sexual }\end{array}$ & 1398 & 93.4 & 2747 & 87.4 & - \\
\hline intercourse & 1326 & 88.6 & 2743 & 87.3 & - \\
\hline \multicolumn{6}{|l|}{ Invalid } \\
\hline Avoid public toilets & 439 & 29.3 & 1028 & 32.7 & 0.0001 \\
\hline Avoid insect bites & 415 & 27.7 & 858 & 27.3 & NS \\
\hline $\begin{array}{l}\text { Avoid sharing food with } \\
\text { someone who has HIV/AIDS } \\
\text { Avoid touching someone who }\end{array}$ & 210 & 14.0 & 638 & 20.3 & $<0.0001$ \\
\hline has HIV/AIDS & 148 & 9.9 & 431 & 13.7 & 0.0001 \\
\hline Have a good diet & 53 & 3.5 & 258 & 8.2 & $<0.0001$ \\
\hline
\end{tabular}

newspapers and magazines as well as the radio. Similar results were found in an Iranian study in 2002 [8].

\section{Marriage and regular partnerships}

Almost $70 \%$ of respondents were sexually active. Males, in general, got married at later ages than females. If we consider those who have had sex and were not married and those who had regular partners apart from spouse, especially since some had multiple partners, the rates are close to those in some studies in other countries, for example, $13 \%$ in St. Petersburg in Russia [9]. Since there was a high belief in the fidelity of the partner, the risk for sexual transmission of HIV could be exacerbated.

Cumulatively, all the risk factors will be predisposing to HIV transmission among married couples, especially among the young and middle-aged couples. The risk is augmented when the time of first sexual experience is taken into consideration. About one-third first experienced sexual intercourse before the age of 21 years and more than half did not respond. This can be compared with reports on young people in the United States of America, which indicate that over two-thirds of the youth participated in heterosexual intercourse prior to age 17 years [10]. Such behaviour is associated with higher risk, and young men rapidly evolve towards engaging in risky behaviours, probably an indication of the education and awareness vacuum in which young people "come of age" in Lebanon and elsewhere $[10,11]$. Therefore, all parameters that add to the risk of acquiring HIV infection were present to a significant extent.

\section{Condom use}

Although $16.8 \%$ of the sexually active people were at risk of HIV infection in 2004, only $71.7 \%$ used condoms in relations with non-regular partners, behaviour which increases the risk of HIV transmission.

More work should be done with a view to promoting a basic change in the attitude of younger males towards condom usestudents had the highest rate for casual sex but the lowest rate for condom use- 




and making condoms more available in suburban and rural areas. In addition, the issue of "fidelity of the partner" should be addressed. No clear-cut conclusion could be reached with regard to females because of the small number that used condoms. It is of interest to point out that no one mentioned the cost of condoms as a barrier.

Despite the fact that $87.3 \%$ of the participants knew that condoms could protect from HIV/AIDS, less than $15 \%$ of those who were sexually active had used them, a great deterioration from about $50 \%$ in 1996. Although the utilization rate was low, it was still better than in some studies, for example, the utilization rate was only $6 \%$ in one American study, and many of the respondents did not believe condoms protected against AIDS transmission [12].

The prevention indicators related to condoms showed that they were available and accessible, but to a lesser extent than in the 1996 survey. There is no doubt about the availability of condoms in the market (pharmacies, supermarkets, gas stations) but the total number available would constitute only a small fraction of the projected needs for the sexually active population fraction.

\section{Sexually transmitted diseases and health issues}

Significant efforts should be deployed towards proper management of STDs since in many cases those reporting having symptoms were not seeking professional treatment. Attitude to the partner had also worsened for many indicators.

Similar efforts should be oriented towards the promotion of proper protective measures, especially the use of condoms since they were not used as the first choice in prevention methods in risky behaviours.

More effort should be deployed to encourage all those who suspected they may have STD to seek professional help since

المجلة الصحية لشرق المتوسط، منظمة الصحة العالمية، المجلد الخنامس عشر، العدد ع، 9 .. 
over $20 \%$ still said they had sought the advice of a friend or a relative first rather than professional advice. Comparing the 2004 data with that of 1996 survey, we noted an increased reporting rate and a statistically significant decrease in recurrent episodes. This could be a sign of increased awareness and improved management since fewer said they would get advice from a friend or do nothing. However, more people would use self-medication rather than get professional advice. This could be an indication of low accessibility to health care or particularly inadequate health-care-seeking behaviour.

\section{Knowledge of AIDS}

The survey results indicated that awareness of AIDS had become almost universal in Lebanon by 2004. Nevertheless, over one-third of the participants endorsed some inappropriate practices for prevention and the rates for most of these misconceptions had deteriorated significantly since 1996. Clearly, inappropriate and invalid practices should be tackled in future campaigns. In addition, some work should be deployed to clarify another important misconception: the fact that persons who have HIV/AIDS do not always show symptoms.

The respondents had a low perception of personal risk: only a quarter had introduced behavioural changes in their lifestyle during the previous year. This perception of low vulnerability was greater in females and is probably reflected in their more positive attitudes towards the HIV/AIDS patients. The only negative point in this context was the view of the majority of respondents that HIV status should be revealed. This issue of confidentiality is still raising debate, and needs to be addressed in future campaigns.

Comparison of the prevention indicators in 1996 and 2004 shows a decrease in awareness, knowledge of protection methods and belief in personal protection. This indicates that a certain level of misconception was still prevailing in the population, which could lead to negative attitudes towards HIV/AIDS patients. The data suggest that current education programmes regarding sex and AIDS are not impacting on the Lebanese people. Similar findings were encountered in a Russian study [9].

\section{HIV/AIDS effect on beliefs, attitudes and lifestyle}

The perception of personal risk could have been the basis for many risky behaviours and lifestyles adopted by a significant proportion of respondents (casual sex, not using condoms, multiple partners, etc.). Coupled with the high rate of belief in self-protection, this did not, as expected, lead to significant behaviour changes. This was a reflection of the respondents' own perception of low vulnerability to infection generally in those who were well educated, young, and well aware of the methods of protection against the disease.

\section{Recommendations}

Taking into consideration the diversity of the Lebanese society and the differences demonstrated in this study, interventions should be more targeted, addressing specific communities and groups for better outreach and impact.

Risk perception should be addressed more in future campaigns, along with misconceptions. The concept of "safe sex" needs to be emphasized and prevention (condoms) need to be better promoted and made more accessible.

More studies need to be done to assess the prevalence and type of STDs, with emphasis on determinants of sexual behaviour as well as health seeking behaviour in patients with STDs. 


\section{References}

1. 2004 Report on the global AIDS epidemic. Geneva, UNAIDS, 2004.

2. The work of WHO in the Eastern Mediterranean Region: annual report of the director 2003. Cairo, World Health Organization Regional Office for the Eastern Mediterranean, 2004.

3. Mokhbat $\mathrm{J}$ et al. The acquired immunodeficiency syndrome: first case in Lebanon. Lebanese medical journal, 1985, 35(4):295-319.

4. Report of the National AIDS Programme. Beirut, Lebanon, Ministry of Health, 2004.

5. Jurjus A. Knowledge, attitudes, beliefs and practices of Lebanese in relation to HIV/AIDS. Beirut, Lebanon, National AIDS Program Reports, 1996.

6. AIDS/HIV national strategic plan, Lebanon 2004-2009. Beirut, National AIDS Control Programme and Ministry of Public Health, 2003.

7. Evaluation of a national AIDS programme: a methods package. Geneva, UNAIDS \& World Health Organization, 1999 (UNAIDS Best Practice Collection: UNAIDS/99.7E).

8. Asghari SHet al. A study on the knowledge and attitudes about the mode of transmis- sion and prevention of AIDS among persons who came for pre-marriage exam to Shadid Haseminejad Laboratory in 2001 (1380). Poster exhibition: XIV International AIDS Conference. Tehran, School of Public Health and Institute of Health Research, Tehran University of Medical Sciences (Abstract no. ThPeF8087).

9. Amirkhanian YA, Kelly JA, Issayer DD. AIDS knowledge, attitudes and behavior in Russia: results of a population-based, random-digit telephone survey in St. Petersburg. International Journal of STD and AIDS, 2001, 12(1):50-8.

10. Brow LK, Diclemente RJ, Park T. Predictors of condom use in sexually active adolescents. Journal of adolescent health, 1992; 13:651-7.

11. Adib SM et al. Heterosexual awareness and practices among Lebanese male conscripts. Eastern Mediterranean health journal, 2002, 8(6):765-75.

12. Adams JL. AIDS knowledge and sexual attitudes/behavior in a middle-class, Midwestern, conservative college freshman population. Ohio journal of science, 90(5):160-70. 